\title{
1 Combined effects of migration distance, foraging method vegetation 2 density, and population density on wing shapes of boreal songbirds
}

3 Flavie Noreau, Centre d'étude de la forêt, Université Laval, Pavillon Abitibi-Price, 2405 rue de la

4 Terrasse, Québec, Qc, GIV0A6 CANADA [flavie_noreau@hotmail.com]

5 André Desrochers, Centre d'étude de la forêt, Université Laval, Pavillon Abitibi-Price, 2405 rue

6 de la Terrasse, Québec, Qc, GIV0A6CANADA [andre.desrochers@sbf.ulaval.ca]

7 For correspondence :

8 André Desrochers, Centre d'étude de la forêt, Université Laval, Pavillon Abitibi-Price, 2405 rue de

9 la Terrasse, Québec, Qc, GIV OA6 CANADA

10 Email : andre.desrochers@sbf.ulaval.ca

11 Telephone : 418-656-2131 \# 2908 
12 Combined effects of migration distance, foraging method vegetation density, and population density on wing shapes of boreal songbirds

$14 \quad$ Flavie Noreau and André Desrochers

\section{Abstract}

In birds, migration distance is known to influence morphological attributes that influence flight performance, especially wing shape. However, wing shape is under the likely influence of less documented factors such as foraging method, vegetation density and isolation of individuals and populations. To better understand factors leading to interspecific differences in wing shape, we measured the pointedness of wings (Kipp's distance) of 1017 live birds of 22 species in an eastern Canadian boreal forest. We modeled wing pointedness as a function of migration distances from eBird records, foraging, habitat, and population density data from Birds of North America monographs. Long-distance migrants and species living in low-density vegetation had more pointed wings than shorterdistance migrants and dense-vegetation dwellers, in accordance to our predictions. After accounting for vegetation density and migration distance, we found no link between the extent of aerial foraging or mean breeding population density, an indicator of isolation, and wing pointedness. Those results are consistent with a tradeoff between sustained flight efficiency and maneuverability, but suggest that interspecific variation in wing shape due specifically to foraging method or habitat isolation is nonexistent or obscured by other 31 factors.

\section{MIGRATION, MORPHOLOGY}




\section{Introduction}

35 Variation in wing shape is constrained by aerodynamic principles, but it remains highly variable from one species to another. In the case of birds, elongated wings with short secondary remiges and long primary remiges facilitate sustained flight (Bowlin and Wikelski 2008) while rounder wings are thought to facilitate maneuverability (Savile 1957). Wing shape is associated to migratory performance in mammals and birds (Palmer 1900; Norberg and Rayner 1987). This association has been shown with Palearctic warblers (Marchetti et al. 1995; Nowakowski et al. 2014), Nearctic thrushes (Dilger 1956) and swallows (Huber et al. 2016), seven Palearctic and Nearctic passerine genera (Mönkkönen 1995), as well as shorebirds (Burns 2003; Minias et al. 2015). North American passerines may provide an exception to this rule (Keast 1980; Niemi 1985), but no quantitative evidence exists to assess this claim.

Once migration is completed, birds are subject to further selective pressure on functional traits related to flight, and at very different spatial scales (Huber et al. 2016). For species gleaning food on the ground, perched or in dense vegetation, the advantages of manoeuvrability may overwhelm the need for efficient sustained flight (Dilger 1956; Niemi 1985). Isolation from conspecifics and concomitant movement may exert evolutionary pressure independent of migration distance, in favor of elongated wings (Desrochers 2010).

While their roles are often speculated upon, foraging method, vegetation density and population isolation remain poorly documented correlates of avian wing shape.

In this study we link bird wing pointedness, more specifically the projection of primary flight feathers also known as Kipp's distance (Lockwood et al. 1998), and four important aspects of their ecology: migration distance, foraging method, breeding habitat density and isolation. With boreal forest songbirds, we test the following hypotheses: wings are more pointed in species 1) with longer migration distances; 2) more frequently using aerial foraging tactics such as hovering and sallying; 3) foraging in sparse vegetation; and

60 4) found in low-density breeding populations. 


\section{Materials and methods}

\section{Study Area}

63 We conducted field work at Forêt Montmorency, Quebec, Canada (47.4 N, 71.1W) during

64 the summers 2013 and 2014. This forest has been managed for timber since the early

65 1930's, with ecosystem management (Bélanger 2001; Gauthier et al. 2008) dominating the

66 southern half of the territory, and large (100-150 ha) clearcuts dominating the northern half.

67 Young stands (<20 y) are generally a dense mixture of deciduous and coniferous species

68 (Mallik et al. 2014), but older stands are largely dominated by balsam fir (Abies balsamea

69 (L.) Mill.), with occasional groves of spruce (Picea glauca (Moench) Voss, Picea mariana

70 (Mill.) Britton), birch (Betula papyrifera Marsh.) and poplar (Populus tremuloüdes Michx.,

71 Populus balsamifera L.).

\section{Wing pointedness}

73 We captured birds in mist nets at 30 sites throughout the $412 \mathrm{~km}^{2}$ study area. We deployed 74 nets between 5 am and 11 am over 2 or 3 consecutive days at each site. We used recordings 75 of mobbing calls (Gunn et al. 2000) and species songs to increase capture rates. We 76 banded, identified and measured birds with age and sex determined by plumage (Pyle 1997). To facilitate the measurements of wing pointedness, we took one to three photos of the right wing flattened on a wing ruler for each bird, with a Nikon D80 digital SLR with a resolution of 10 Megabytes in 2013 and Nikon D7100 DSLR 24 megabytes in 2014. We took measurements in pixels from each photo with an image processing software, ImageJ (http://imagej.nih.gov/ij/). Two lengths were obtained: a) the total length of the folded, flattened, wing, and b) the length between the posterior end of the most distal secondary feather and the posterior end of the wing (Fig. 1). Wing pointedness was quantified as the ratio b/(a+b) (Lockwood et al. 1998).

Repeated (blind) estimates of the wing pointedness of the same bird by the same author had a mean standard deviation of $0.27 \mathrm{~mm}(n=666$ birds $)$, and a coefficient of variation of $1.6 \%$. The mean standard deviation of wing pointedness estimates of the same 
precision and accuracy of wing pointedness estimates were sufficiently high to yield useful

90 interspecific comparisons.

\section{Aerial Foraging, Vegetation Density, and Population Density}

92 We characterized foraging method, vegetation density, and breeding population density 93 with monographs from The Birds of North America Online, BNA (Rodewald 2015). For

94 foraging method, we estimated for each species the proportion of time spent gleaning while 95 perched or on the ground, hovering (picking prey in flight, from substrate), and sallying 96 (flying from perch to catch flying prey, (Eckhardt 1979)). When available, quantitative 97 estimates we used, otherwise we attributed $10 \%$ of the time for foraging methods depicted as "occasional" (including "common", "frequent", "sometimes") and 5\% for method rarely used (including "seldom"), leaving the rest to the most frequently used method. We calculated an aerial foraging index as a weighted sum, with weights of 1, 2, and 3 for gleaning, hovering and sallying respectively (possible range 1-3; Table 1).

For vegetation density, we made a systematic search of words qualifying density using the "Habitat" section of the BNA account of each species. The search was divided between breeding and winter ranges. We sought words related to shrub layers, "shrub", "bush", "scrub", "dense", "thick", and measured the location of first occurrence of one of these words ( $n$th word in the Habitat section). The relative position of the word in the text $(100 \%=$ first, $0 \%=$ last $)$ was taken as an indicator of weight. We assume that keywords used earlier in the paragraph provided evidence for a stronger link to dense cover than those listed towards the end of the text. We added ratings computed for the breeding as well as the wintering season to obtain a vegetation density index for each species (Table 1).

We calculated the mean breeding population density of each species from all the breeding density estimates cited in the BNA species accounts (Table 1). In the case of the little-known Bicknell's Thrush (Catharus bicknelli) we used Rimmer et al. (1996) . 


\section{Migration distance}

115 To assign average species migration distances, we used the eBird database (Sullivan et al.

116 2009). This site was developed by the Cornell Lab of Ornithology and the National

117 Audubon Society and contains millions of bird sightings throughout the world. We

118 obtained coordinates, rounded to the nearest degree of latitude and longitude, of each

119 observation in January and February (i.e. wintering) for all bird species considered in this

120 study, as well as the total observation effort in minutes. Multiple records of a species in the

121 same latitude/longitude on the same year were reduced to one to prevent bias due to

122 repeated observations (e.g. stragglers attracting large numbers of birders). For each eBird

123 entry ( $n=445,512$, Table 1$)$, we calculated the great-circle distance from the geographic

124 center of the Forêt Montmorency using the 'sp' package of R software (Pebesma and

125 Bivand 2005; Bivand et al. 2013).

\section{Statistical analysis}

127 Studies comparing mean attributes from multiple species may suffer from a lack of true replication because of phylogenetic proximity among subsets of the species. To account for this, we obtained phylogenetic trees of the species studied, from Jetz et al. (2012). Because of uncertainty in the relationship between DNA data and years since speciation, phylogenetic trees are only approximations based on various assumptions about the rate of phylogenetic divergence. Thus, we generated 10,000 phylogenetic trees (Fig. 2) and established phylogenetic distances for each dyad from the 22 study species (Paradis et al. 2004). index, vegetation density index, and population density on wing pointedness with a linear model using phylogenetic Generalized Least Squares (pGLS). The pGLS method accounts for the phylogenetic distance between species by using a distance covariance matrix which gives more weight to differences in wing pointedness between remote species phylogenetically than in wing pointedness of closely related species (Felsenstein 1985;

141 Grafen 1989; Harvey and Pagel 1991). We ran 10,000 pGLS models, corresponding to each

142 of the 10,000 phylogenetic trees of all species. We calculated summary statistics from those 
14310,000 models for regression coefficients, their standard error, and $p$ values. Data analyses

144 were conducted in R, using the 'ape' (Paradis et al. 2004), 'nlme' (Pinheiro et al. 2016),

145 and 'phylolm' (Ho and Ané 2014).

\section{$146 \quad$ Results}

147 We considered 22 different bird species, that is, all species with at least five specimens 148 captured ( $n=1017$; Table 1$)$. Intraspecific variance of wing pointedness was significantly 149 lower than interspecific variance $\left(\mathrm{F}_{21,995}=266.2 ; p<0.001\right)$, thus we assume that mean 150 estimates for each species were sufficiently contrasted for comparative analysis. Vegetation 151 density and aerial foraging indices were not significantly, correlated $\left(r_{s}=0.1, p=0.6\right.$, $152 n=22)$. negatively associated to vegetation density (Fig. 4) with all phylogenetic trees (Table 2). Results were similar when the 'outlier' species with shortest and longest migration distances (Fig. 3) were removed. We found no relationship between wing pointedness, aerial foraging or breeding population density (Table 2) Results obtained with a multiple regression ignoring phylogenetic effects were highly similar for migration distance (estimate $=2.20 \mathrm{e}-5 \pm 5.9 \mathrm{e}-6, p<0.001$ ), aerial foraging (estimate $=8.87 \mathrm{e}-4 \pm 2.0 \mathrm{e}-2, p=$ 0.9 ), vegetation density (estimate $=-1.87 \mathrm{e}-2 \pm 7.1 \mathrm{e}-3, p=0.02$ ), and breeding population density (estimate $=-2.38 \mathrm{e}-4 \pm 9.1 \mathrm{e}-3, p>0.9)$.

\section{Discussion}

163 As we predicted, wing pointedness was greater in species that performed longer migration and smaller in species living in more densely vegetated environments. However, the amount of aerial foraging and population density had no explanatory power. The low variance of estimates between GLS models suggests that interspecific differences in wing shape and length (i.e. wing pointedness) were not greatly affected by uncertainty in phylogenetic relationships. Mönkkönen (1995)), at least a dozen studies have provided evidence for more pointed or 
171 longer wings longer-distance migrants than conspecifics that migrate shorter distances (de

172 La Hera et al. 2010; Rushing et al. 2014), or sedentary ones (Milá et al. 2008). Similar

173 results were found in studies focusing on interspecific differences (Mönkkönen 1995;

174 Minias et al. 2015). The present results, nearly half of which were obtained from north

175 American warblers (Parulidae), are contrary to the earlier suggestions by Keast (1980) and

176 Niemi (1985) that wing shape of those birds was unrelated to migration distance. Instead,

177 this study adds to a growing body of evidence for a generally positive relationship between

178 migratory behavior and wing attributes that facilitate sustained flight.

A notable exception to the wing shape - migration distance rule is the recent link between migration distance and wing pointedness, which they interpret as related to the swallows' aerial foraging behavior which resembles their migratory flight, contrary to most other species whose wing pointedness vs. migration has been investigated so far. Earlier studies also pointed to the importance of foraging behavior as a determinant of wing pointedness, in bats (Baagøe 1987) and birds (Savile 1957; Marchetti et al. 1995;

Vanhooydonck et al. 2009). Contrary to expectation, our results did not suggest a link between wing pointedness and aerial foraging per se, possibly because of insufficient variation in foraging methods among the 22 species, a lack of precision in our assessment of aerial foraging, or a combination of both. It would therefore be premature to rule out an ecomorphological effect of foraging behavior in itself on wing shape, at least in boreal songbirds.

Vegetation density has long been proposed as influencing wing shape, with longerwinged species found in more open habitats (Linsdale 1938). Rounded wings are often thought to allow better maneuverability, an asset in cluttered habitats (Norberg 1979). Furthermore, less pointed wings could facilitate predator escape on takeoff (Swaddle and Lockwood 2003; Fernández and Lank 2007), also advantageous mostly in dense cover. The present study is the first to provide evidence for a direct relationship between vegetation density and wing pointedness, but it would be premature to generalize to a broader set of species, because here we focused on a specific group of birds, i.e., small-sized forest birds predominantly foraging on standing vegetation or the ground. 
201 Contrary to our expectation, there was no significant link between population

202 density, which we assume reflects isolation (negatively), and wing pointedness. This could

203 be due to insufficient precision in breeding population densities measures caused by the

204 patchy records reported in BNA (Poole 2005) for most species. For example, those

205 estimates do not distinguish between situations where a species would be found in dense

206 clusters at the habitat patch scale, but scarce at the landscape scale, vs. uniformly scattered

207 pairs throughout a landscape. Such differences could greatly affect the level of isolation

208 experienced by individual members of the species. Furthermore, the population density of

209 certain bird species may vary greatly from one region to another, as well as between

210 wintering and nesting areas (Sherry and Holmes 1996). Unfortunately, there are few data

211 on population densities in the wintering grounds. Regardless of data availability, it is

212 perhaps unrealistic to expect that a species can be reduced to a single population density,

213 because of the substantial geographic variation which is likely to occur.

214 Despite the latter caveats, the use of a comparative approach between different

215 species of the same group still remains a useful approach to understand general patterns of

216 habitat use in association to wing morphology. The accumulation of evidence on correlates

217 of avian wing shape should not only lead to a better understanding of ecological differences

218 among species, but opens the way for more incisive comparative analyses testing

219 predictions about avian responses to ever-changing environments.

\section{Acknowledgements}

221 Thanks to Vanessa Dufresne, Pierre-Alexandre Dumas, Jean-Michel Chabot and all

222 volunteers, for their help in the field, and to the staff at Forêt Montmorency (Université

223 Laval) for logistical support. This project was funded by an NSERC grant 170173 to AD,

224 with authorization from Université Laval's animal care committee (2013030-2). 


\section{References}

Baagøe, H.J. 1987. The scandinavian bat fauna: adaptive wing morphology and free flight in the field. In Advances in the study of bats. Edited by M. B. Fenton. Cambridge University Press, Cambridge, UK. pp. 57-74.

Bélanger, L. 2001. La forêt mosaïque comme stratégie de conservation de la biodiversité de la sapinière boréale de l'Est: l'expérience de la Forêt Montmorency. Nat. Can. 125(3): 18-25.

Bivand, R.S., Pebesma, E., and Gomez-Rubio, V. 2013. Applied spatial data analysis with R, Second edition. Springer, New York, NY, USA.

Bowlin, M.S., and Wikelski, M. 2008. Pointed wings, low wingloading and calm air reduce migratory flight costs in songbirds. PLoS ONE 3(5): e2154.

Burns, J.G. 2003. Relationship of Calidris sandpiper wing shape with relative fuel load and total migration distance. The Auk 120(3): 827-835.

de La Hera, I., Pérez-Tris, J., and Tellería, J.L. 2010. Migratory behavior and differential resource allocation between wing and tail feathers in a passerine bird. The Auk 127(3): 647-652. doi:10.1525/auk.2010.09120.

Desrochers, A. 2010. Morphological response of songbirds to 100 years of landscape change in North America. Ecology, 91(6): 1577-1582. doi:10.1890/09-2202.

Dilger, W.C. 1956. Adaptive modifications and ecological isolating mechanisms in the thrush genera Catharus and Hylocichla. The Wilson Bulletin 68: 170-199.

Eckhardt, R.C. 1979. The adaptive syndromes of two guilds of insectivorous birds in the Colorado Rocky Mountains. Ecol. Monogr. 49(2): 129-149.

Felsenstein, J. 1985. Phylogenies and the Comparative Method. The American Naturalist 125(1): 1-15.

Fernández, G., and Lank, D.B. 2007. Variation in the wing morphology of Western Sandpipers (Calidris mauri) in relation to sex, age class, and annual cycle. The Auk 124(3): 1037-1046. doi:10.1642/0004-8038(2007)124[1037:vitwmo]2.0.co;2.

Gauthier, S., Vaillancourt, M.-A., Leduc, A., De Grandpré, L., Kneeshaw, D., Morin, H., Drapeau, P., and Bergeron, Y. (eds). 2008. Aménagement écosystémique en forêt boréale. Presses de l'Université du Québec, Québec, QC, Canada.

Grafen, A. 1989. The phylogenetic regression. Philosophical Transactions of the Royal Society of London. Series B, Biological Sciences 326(1233): 119-157.

Gunn, J.S., Desrochers, A., Villard, M.-A., Bourque, J., and Ibarzabal, J. 2000. Playbacks of mobbing calls of Black-capped Chickadees as a method to estimate reproductive activity of forest birds. J. Field Ornithol. 71(3): 472-483.

Harvey, P.H., and Pagel, M.D. 1991. The comparative method in evolutionary biology. Oxford University Press, Oxford, UK.

Ho, L.S.T., and Ané, C. 2014. A Linear-time algorithm for Gaussian and non-Gaussian trait evolution models. Syst. Biol. 63(3): 397-408. doi:10.1093/sysbio/syu005. 
Huber, G.H., Turbek, S.P., Bostwick, K.S., and Safran, R.J. 2016. Comparative analysis reveals migratory swallows (Hirundinidae) have less pointed wings than residents. Biological Journal of the Linnean Society. doi:10.1111/bij.12875.

Jetz, W., Thomas, G.H., Joy, J.B., Hartmann, K., and Mooers, A.O. 2012. The global diversity of birds in space and time. Nature, 491(7424): 444-448.

Keast, A. 1980. Spatial relationships between migratory parulid warblers and their ecological counterparts in the Neotropics. In Birds in the Neotropics: ecology, behavior, distribution and conservation. Edited by A Keast, and E. S. Morton. Smithsonian Institution Press, Washington, D.C. pp. 109-130.

Linsdale, J.M. 1938. Bird life in Nevada with reference to modifications in structure and behavior. The Condor 40(4): 173-180.

Lockwood, R., Swaddle, J.P., and Rayner, J.M.V. 1998. Avian wingtip shape reconsidered: wingtip shape indices and morphological adaptations to migration. J. Avian Biol. 29(3): 273-292.

Mallik, A.U., Kreutzweiser, D.P., and Spalvieri, C.M. 2014. Forest regeneration in gaps seven years after partial harvesting in riparian buffers of boreal mixedwood streams. For. Ecol. Manage. 312: 117-128. doi:http://dx.doi.org/10.1016/j.foreco.2013.10.015.

Marchetti, K., Price, T., and Richman, A. 1995. Correlates of wing morphology with foraging behaviour and migration distance in the genus Phylloscopus. J. Avian Biol. 26(3): 177-181.

Milá, B., Wayne, R.K., and Smith, T.B. 2008. Ecomorphology of migratory and sedentary populations of the Yellow-rumped Warbler (Dendroica coronata). The Condor 110(2): 335-344.

Minias, P., Meissner, W., Włodarczyk, R., Ożarowska, A., Piasecka, A., Kaczmarek, K., and Janiszewski, T. 2015. Wing shape and migration in shorebirds: a comparative study. Ibis, 157(3): 528-535. doi:10.1111/ibi.12262.

Mönkkönen, M. 1995. Do migrant birds have more pointed wings?: A comparative study. Evol. Ecol. 9(5): 520-528.

Niemi, G.J. 1985. Patterns of morphological evolution in bird genera of New World and Old World peatlands. Ecology, 66: 1215-1228.

Norberg, U.M. 1979. Morphology of the wings, legs and tail of three coniferous forest tits, the goldcrest, and the treecreeper in relation to locomotor pattern and feeding station selection. Philosophical Transactions of the Royal Society of London B: Biological Sciences 287(1019): 131-165.

Norberg, U.M., and Rayner, J.M.V. 1987. Ecological morphology and flight in bats (Mammalia; Chiroptera): wing adaptations, flight performance, foraging strategy and echolocation. Philosophical Transactions of the Royal Society B: Biological Sciences 316(1179): 335-427. doi:10.1098/rstb.1987.0030.

Nowakowski, J.K., Szulc, J., and Remisiewicz, M. 2014. The further the flight, the longer the wing: relationship between wing length and migratory distance in Old World 
reed and bush Warblers (Acrocephalidae and Locustellidae). Ornis Fenn. 91(3): 178-186.

Palmer, W. 1900. Ecology of the Maryland yellow-throat, and its relatives. The Auk 17(3): 216-242.

Paradis, E., Claude, J., and Strimmer, K. 2004. APE: analyses of phylogenetics and evolution in R language. Bioinformatics, 20(2): 289-290.

Pebesma, E.J., and Bivand, R.S. 2005. Classes and methods for spatial data in R. R News 5 (2 ( http://cran.r-project.org/doc/Rnews/)).

Pinheiro, J., Bates, D., DebRoy, S., Sarkar, D., and R Core Team. 2016. nlme: Linear and Nonlinear Mixed Effects Models. R package version 3.1-128, <URL: http://CRAN.R-project.org/package=nlme>.

Poole, A. (ed). 2005. The Birds of North America Online: http://bna.birds.cornell.edu/BNA/. Cornell Laboratory of Ornithology, Ithaca, NY, USA.

Pyle, P. 1997. Identification guide to North American birds, Part I. Slate Creek Press, Bolinas, CA, USA.

Rimmer, C.C., Atwood, J.L., McFarland, K.P., and Nagy, L.R. 1996. Population density, vocal behavior, and recommended survey methods for Bicknell's Thrush. The Wilson Bulletin: 639-649.

Rodewald, P.G. (ed). 2015. The Birds of North America: https://birdsna.org. Cornell Laboratory of Ornithology, Ithaca, NY, USA.

Rushing, C.S., Ryder, T.B., Saracco, J.F., and Marra, P.P. 2014. Assessing migratory connectivity for a long-distance migratory bird using multiple intrinsic markers. Ecol. Appl. 24(3): 445-456.

Savile, D.B.O. 1957. Adaptive evolution in the avian wing. Evolution, 11(2): 212-224.

Seebohm, H. 1901. The Birds of Siberia: A Record of a Naturalist's Visits to the Valleys of the Petchora and Yenesei. J. Murray.

Sherry, T.W., and Holmes, R.T. 1996. Winter habitat quality, population limitation, and conservation of neotropical-nearctic migrant birds. Ecology, 77(1): 36-48.

Sullivan, B.L., Wood, C.L., Iliff, M.J., Bonney, R.E., Fink, D., and Kelling, S. 2009. eBird: a citizen-based bird observation network in the biological sciences. Biol. Conserv. 142: 2282-2292.

Swaddle, J.P., and Lockwood, R. 2003. Wingtip shape and flight performance in the European Starling Sturnus vulgaris. Ibis, 145(3): 457-464.

Vanhooydonck , B., Herrel, A., Gabela, A., and Podos, J. 2009. Wing shape variation in the medium ground finch (Geospiza fortis): an ecomorphological approach. Biological Journal of the Linnean Society 98(1): 129-138. doi:10.1111/j.1095-

8312.2009.01269.x. 
Table 1. Species characteristics. Species ordered according to their estimated phylogenetic tree.

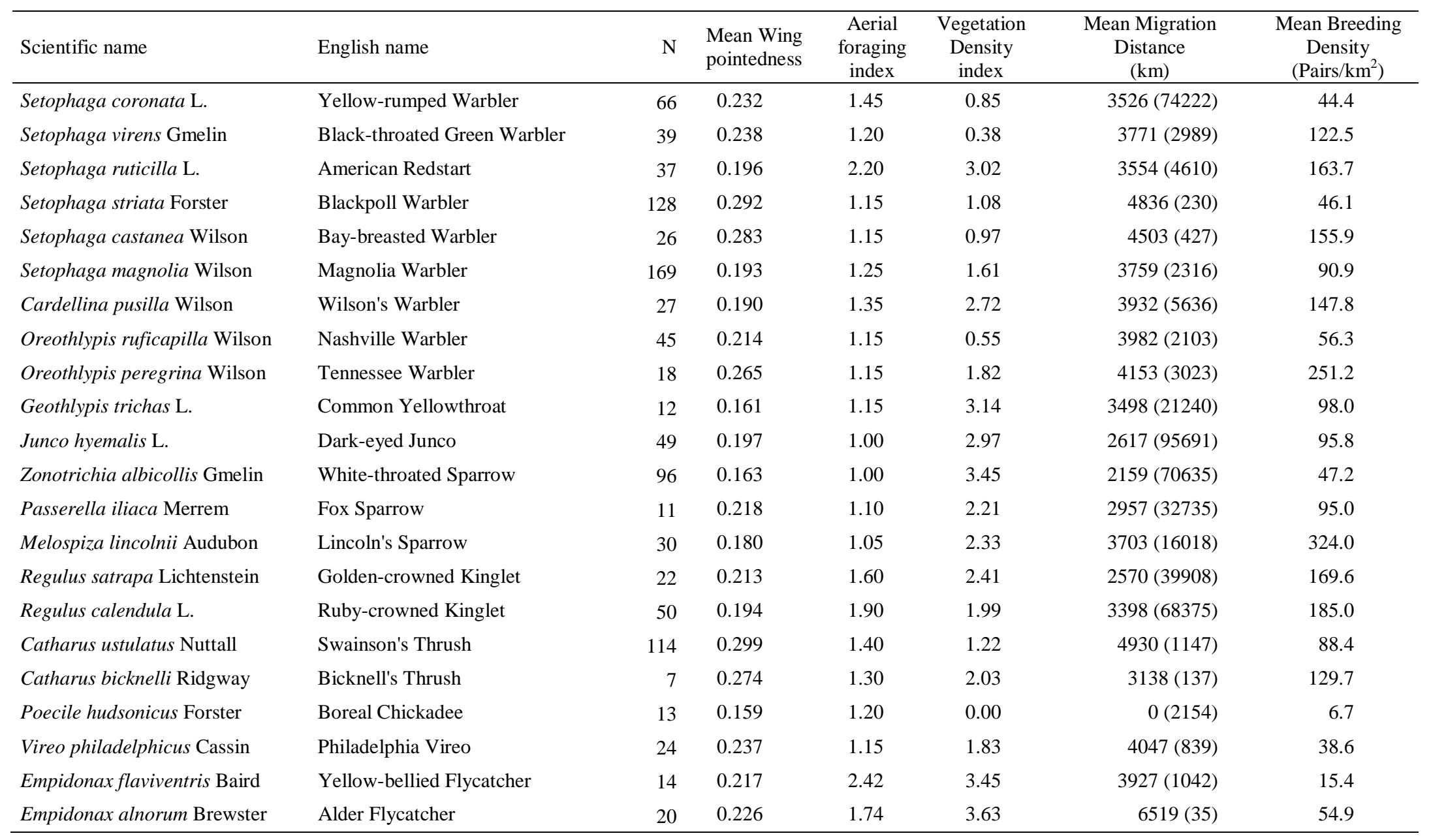


Table 2. Means and ranges of GLS model estimates and p-values for 10,000 trees for relationship between wing pointedness, Aerial foraging Index, Vegetation Density Index, Migration Distance and Breeding Population Density ( $N=22$ species).

\begin{tabular}{lrrr}
\hline & \multicolumn{1}{c}{ Estimate } & \multicolumn{1}{c}{$p$} \\
\hline Aerial Foraging Index & - & & \\
Vegetation Density Index & $0.0000100[-0.00122,0.00148]$ & $0.99[0.94,1]$ \\
& $-0.0184[-0.0190,-0.0181]$ & $0.021[0.018,0.024]$ \\
Migration Distance (per 1000 km) & $0.0221[0.0218,0.0225]$ & $0.002[0.0020,0.0024$ \\
Breeding Population density (per 100 & $0.016[-0.035,0.078]$ & $2]$ \\
$\left.\mathrm{km}^{2}\right)$ & & $0.98[0.93,1]$ \\
\hline
\end{tabular}




\section{Figures}

Fig. 1. Measurements used to calculate wing pointedness. Red markers (1,2 and 3) were tattooed on photos to facilitate measurements.

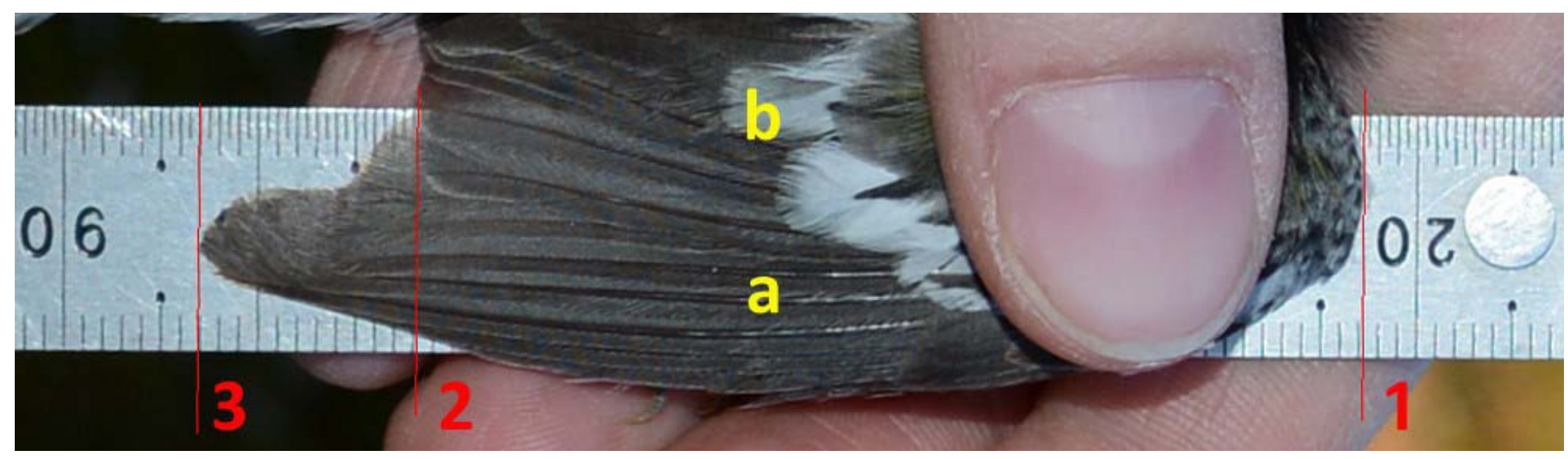


Fig. 2. A phylogenetic tree of the species in the study. Generated from the website "birdtree.org" (Jetz et al. 2014).

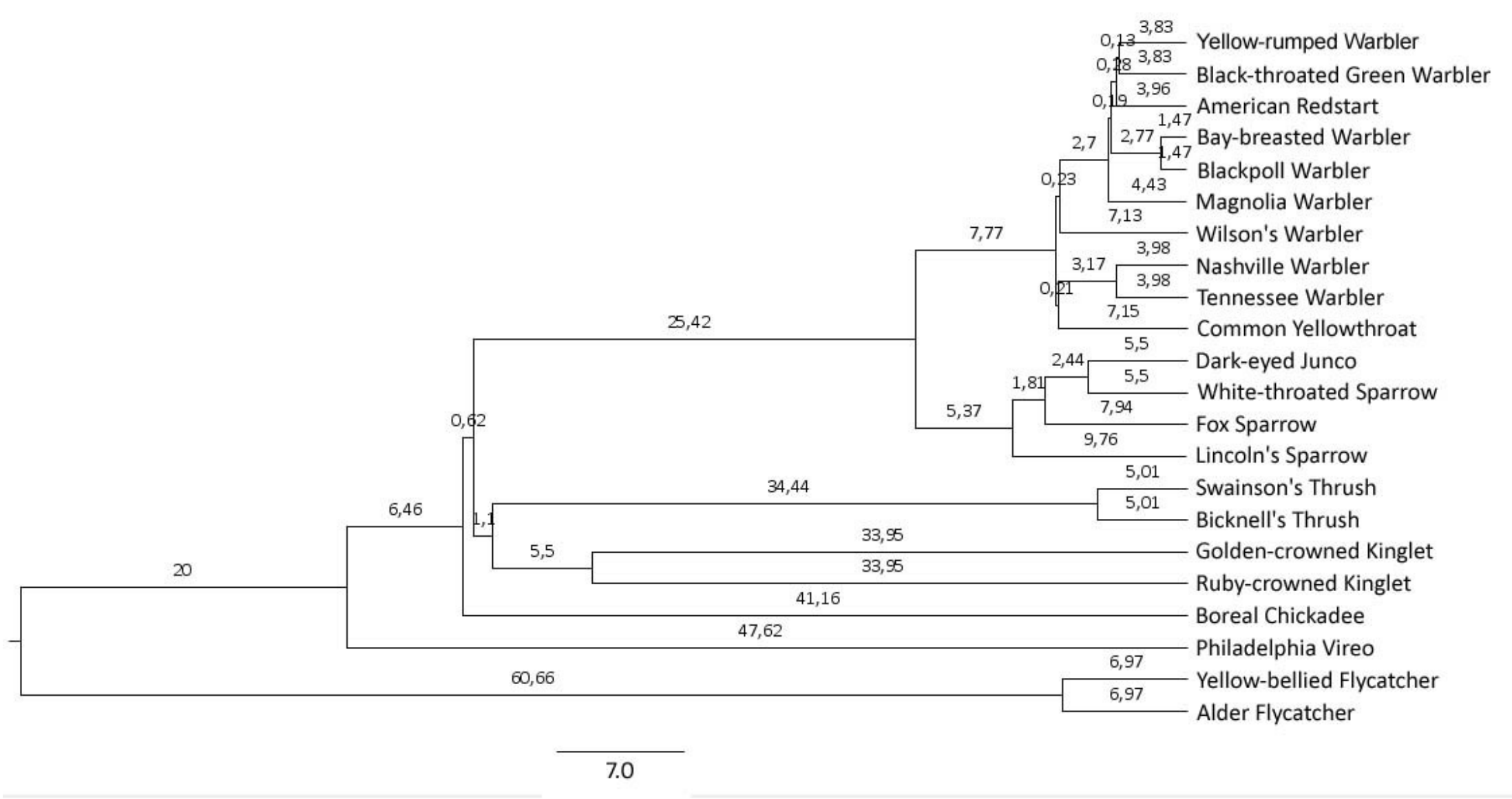


Fig. 3. Wing pointedness in relation with migration distance in kilometers. Each point denotes a species.
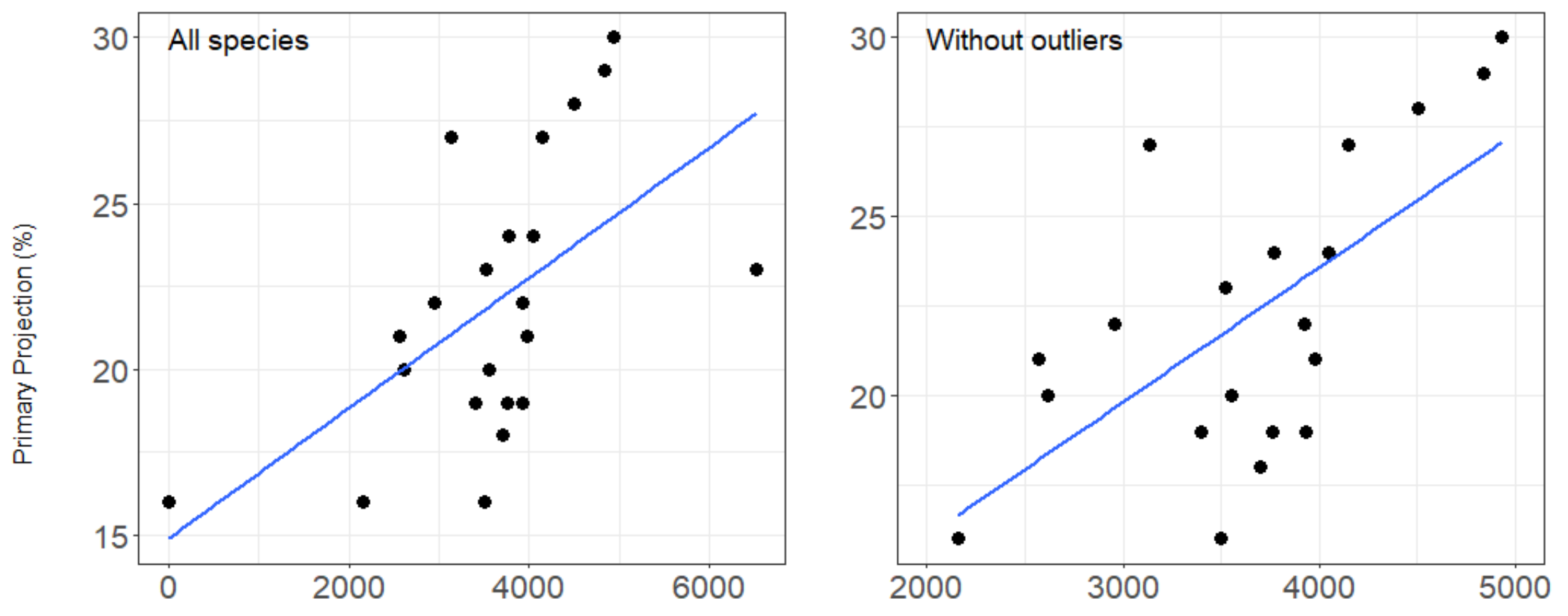

Migration Distance $(\mathrm{km})$ 
Fig. 4. Wing pointedness in relation with vegetation density index. Each point denotes a species.

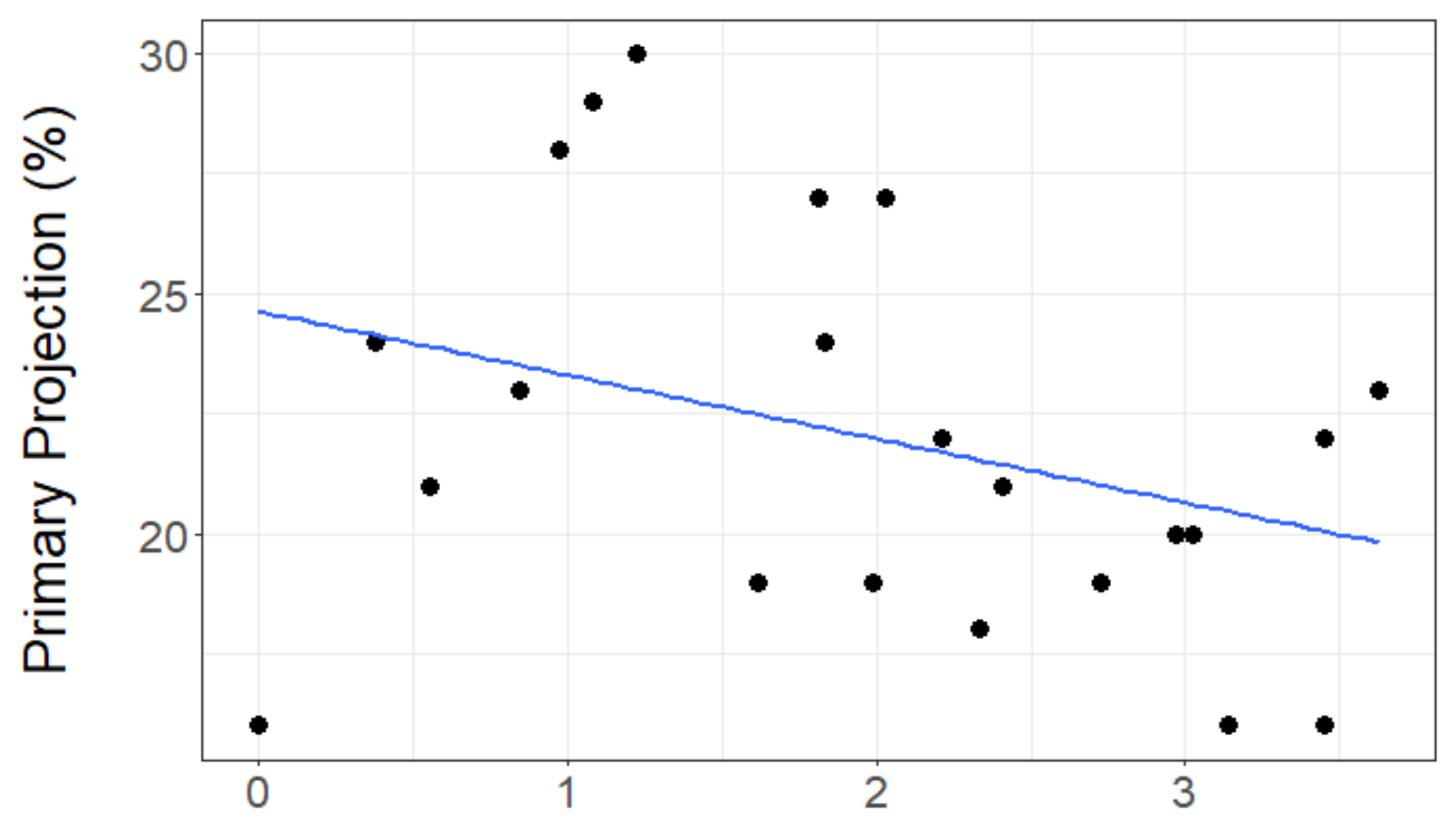

Vegetation Density Index 